\title{
Prevalence and Correlates of Experience of Physical and Sexual Intimate Partner Violence among Men and Women in Eastern DRC
}

\author{
Stella Babalola ${ }^{1, *}$, Amrita Gill-Bailey ${ }^{1}$, Mathurin Dodo ${ }^{2}$ \\ ${ }^{1}$ Center for Communication Programs, Bloomberg School of Public Health, Johns Hopkins University, Baltimore, United States \\ ${ }^{2}$ International Medical Corps, Bukavu, Democratic Republic of Congo \\ *Corresponding Author: sbabalol@jhsph.edu
}

Copyright $(2014$ Horizon Research Publishing All rights reserved.

\begin{abstract}
This manuscript uses large-scale survey data to examine the prevalence and correlates of intimate partner violence (IPV) in the eastern part of the Democratic Republic of the Congo (DRC), namely in North Kivu and South Kivu provinces. We examine two form of IPV: physical and sexual. The data show that two of every five women and more than one quarter of men had reportedly ever experienced physical IPV while one quarter of women and 15.7 percent of men reported ever experiencing sexual IPV. The correlates of IPV differ for men and women and depend on the type of IPV. For men, the strongest correlates of physical IPV include current employment, education and recent experience of sexual IPV. The strongest correlates for experiencing sexual violence among men were young age, problematic use of alcohol, gender-equitable attitudes, province of residence, and recent experience of physical IPV. For women, young age, low education, gender-equitable attitudes, partner problematic use of alcohol, partner controlling behaviors, recent experience of sexual IPV, and recent experience of public humiliation were the correlates of physical IPV. The strongest correlates of sexual IPV for women include province of residence, partner problematic use of alcohol, partner controlling behaviors, and recent experience of physical IPV. The programmatic implications of the findings are discussed.
\end{abstract}

Keywords Intimate Partner Violence, Prevalence, Correlates, DRC

\section{Introduction}

The Democratic Republic of the Congo (DRC) remains one of the countries with the highest prevalence of sexual violence in the world.[1] Sexual and gender-based violence (SGBV; including individual rapes, gang rapes, mutilation of the genital organs, sexual slavery and forced marriages) was widely used as a weapon of war during the protracted conflict that erupted in the eastern part of the country in 1998. Although the armed conflict officially ended in 2003, SGBV continues to be a common occurrence in Eastern DRC.[2] Whereas most of the survivors of SGBV in the region are women, there is an emerging trend in some parts of the region of men being sexually abused.[3] Moreover, although SGBV in Eastern DRC is largely militarized, there is evidence of increased civilian involvement in perpetrating these crimes.[4] Intimate partner violence (IPV) is a form of SGBV perpetrated by a romantic partner, including spouse, ex-spouse, current or former girlfriend or boyfriend. The term covers a wide variety of adverse incidents, including physical abuse, sexual violence (including, forced sex, unsolicited and non-consensual sexual advances), psychological trauma, and controlling behaviors. Although it is common for men to be victims of IPV, the bulk of the IPV burden worldwide is borne by women.[5-8] Studies from around the world have shown that between 15 and 71 percent of women have ever experienced IPV. A World Health Organization (WHO) ten-country study revealed that IPV is very common across countries irrespective of the level of development or cultural background.[9] The study revealed that the proportion of ever-partnered women who had ever experienced sexual violence from an intimate partner varied between 6 percent in Japan to 59 percent in Ethiopia. Similarly, the lifetime prevalence of physical IPV varied between 13 percent in Japan to 61 percent in Peru; in most of the study countries, the lifetime prevalence of physical IPV ranged between 23 percent and 49 percent. Another multi-country study that focused on developing countries (WorldSAFE) found that lifetime prevalence of physical IPV among their urban samples of women varied between 11.1 percent in El-Sheik Zayed, Egypt and 34.6 percent in Lucknow, India [10]

The health and social consequences of IPV for the victim have been well documented and include injury, compromised physical health, emotional trauma, suicide, 
poor reproductive health outcomes and even death. Perhaps the most visible and immediate health consequence of IPV is the physical injury sustained by the victim during the incident, including bruises, welts, sprains, and even fractures.[11-14] In addition to injury, IPV has other physical health consequences. This type of violence has been associated with various forms of functional disorders, including gastrointestinal disorders, chronic pain syndromes, asthma, memory loss, disabilities, and dizziness.[12, 15-18] The mental health consequences of IPV are also enormous and include depressive symptoms, substance use, post-traumatic stress disorder, substance abuse, suicidal thoughts, and suicidal attempts.[11,19-21] The reproductive health consequences of IPV include unwanted pregnancy, miscarriage, induced abortion, infertility, gynecological disorders, pregnancy-related complications, low birth weight, fetal injury, stillbirth and sexually transmitted diseases. $[12,22,23]$ There is considerable evidence that the negative effects of IPV continue even after the abuse has stopped.[11,12,24]

The effects of IPV are not limited to the direct victim; it has consequences for the children as well, specifically if the victim is a woman. The consequences for children include anxiety, poor academic performance, depression, post-traumatic stress disorder, poor health, incomplete immunization, behavioral problems, perpetration of IPV later in life, and increased mortality.[25-29] In a recent review of the literature, Wood and Sommers [29] found that IPV has dose-response short-term and long-term effects on children and affect their relationships with peers and romantic partners later in life.

The causes of IPV are varied and context-specific; they are also still much debated. In a review of literature, Jewkes [30] classified the various causes into two broad categories: (1) culture of violence, and (2) social norms that support male superiority. The culture of violence has to do with the propensity for violence and the extent to which violence is normative as a way of resolving conflict in one's setting. An increasing number of studies from developed and developing countries have highlighted the culture of violence as a cause of IPV. These studies have found that witnessing IPV between parents, personal experience of child abuse, and tolerance for IPV in one's community are the factors commonly associated with IPV perpetration or victimization. [6, 31-35] As Jewkes explained, the notion of male superiority is manifested through gender-inequitable norms, male sexual entitlement, relative powerlessness and low social value of women, and a definition of masculinity that is premised on control of women by men. The notion of male superiority is further reinforced by low education of women, fewer employment opportunities, limited public roles, and lower economic empowerment for women. Violence is used to enforce the notion of male superiority and punish transgressions against the norms that promote this superiority. Unlike the culture of violence hypothesis, a large body of literature supports the idea that the causes of IPV are connected with the notion of male superiority as we will see in the next paragraphs. $[6,9,12,27,36-42]$

Most studies that examined the risk factors for IPV have focused on men as perpetrators and women as victims. The factors identified by these studies operate at various levels of the socio-ecological model, including intra-personal, inter-personal/household, community and societal. At the intra-personal level, the factors associated with a woman's increased likelihood of being a victim of IPV include younger age, large number of children, low level of education, attitudes towards violence, and living away from the extended family. [6,36-38] The interpersonal/household factors that place a woman at risk for experiencing IPV include marital conflict and disharmony, low conjugal decision making power, economic dependence on husband/male partner, type of marital union, man's engagement in multiple sexual partnerships, witnessing IPV between parents, and childhood experience of abuse.[27,31-38] Other interpersonal correlates of IPV include male partner's exposure to parental IPV, male partner's problematic alcohol use, and disparity in educational attainment of both partners, especially where the woman is better educated than her partner.[9,33,34,35,36,39,40]. The community and societal factors that have been linked to increased likelihood of experiencing IPV include poverty, gender-inequitable norms, low status of women, community norms that support IPV, and armed conflict.[12,41]

Although various studies have demonstrated that IPV against men is common in most settings, very few studies have focused on the risk factors for experiencing IPV among men. The few studies that have examined the factors that place men at increased risk for experiencing various types of IPV have found that risk factors include low income, young age, exposure to IPV of parents in childhood, alcohol abuse, intermittent explosive disorder (IED), lack of closeness to mother or maternal figure in childhood, and marital problems.[6,42] Other studies have suggested that experience of IPV by men often results from self-defense or retaliation from their battered or abused female partners. [43-46]

There is a dearth of literature on the factors associated with IPV victimization in Africa. Our intention in this manuscript is to contribute to bridging the knowledge gap by examining the correlates of IPV among men and women in DRC. We define IPV as violence perpetrated by a romantic partner, including spouse, ex-spouse, current or former girlfriend or boyfriend. We focus on sexual and physical forms of IPV in DRC. We estimate the lifetime and current prevalence of these forms of IPV and assess the socio-demographic, relationship and environmental factors associated with recent experience of each type of IPV. We performed separate analyses for men and women.

\section{Subjects and Methods}




\subsection{Sample}

The data analyzed in this paper are derived from a survey conducted in North Kivu and South Kivu provinces in DRC. The two provinces were sub-regions of the former Kivu region and share historical and linguistic background and a long history of ethnic and political tensions. Kiswahili is widely spoken in both provinces. There are also significant cultural similarities between the two provinces. For example, the residents of both provinces are more than 95 percent Christian. Nonetheless, there are some differences in the ethnic composition of the two provinces. Whereas both provinces include a sizable proportion of Banyamulenge (Tutsis of Rwandan descent), the predominant ethnic groups in North Kivu are the Hunde, Nande, and Banyabwisha (Hutu) while in South Kivu, the most common ethnic groups are the Bashi, Balega, Bembe, Bafulero and Bavira.

The survey was conducted between February and March 2012 on behalf of International Medical Corps with funding from the United States Agency for International Development (USAID). In each study province, we selected study participants from two urban and two rural communes. Eligible respondents were selected following a multistage, stratified random sampling process that involved successively selecting quartiers, households and finally respondents. In each of the two provinces, we conducted the survey in a total of 20 quartiers or villages, comprised of five locations (quartiers or villages) from each of the four study sites. The total number of respondents was 2088, including 952 men and 1136 women. During the questions on IPV were directed at respondents who had ever had sex. A total of 1946 (889 men and 1057 women) respondents had ever experienced sexual intercourse; these men and women were the object of the analyses presented in this manuscript. The respondents are representative of the communes from which the sample was selected.

The study was cleared with the Ethics Committee of the Institut National de la Statisque (INS) in Bukavu prior to the commencement of fieldwork. Adequate measures were taken to protect human subjects, including ethical training for interviewers, obtaining informed consent from the participants, face-to-face interviews without a third party, limited access to completed questionnaires, and no individual identifiers on the questionnaire or in the electronic data set. The Johns Hopkins University (Baltimore, USA) Institutional Review Board reviewed and granted the permission to conduct secondary analysis of the data.

\subsection{Measures}

The dependent variable in this paper is experience of IPV assessed using questions taken from the Conflict Tactics Scale (CTS).[47] Two types of measures were used in the analysis: lifetime experience of IPV and experience of IPV in the last 12 months. Furthermore, we examined two forms of IPV for men and women: physical and sexual. Physical
IPV was measured through responses to seven questions that asked if a current or former partner or spouse has ever (or during the past 12 months): "pushed, shook or throw something at you"; "slapped you or twisted your arm"; "kicked you"; "punched you"; "tried to strangle you"; "threaten you with a knife or gun"; and "attach you with a knife or gun". Answering "yes" to any of the seven questions is taken as indicative of experience of physical IPV. To assess experience of sexual IPV, the respondents were asked if a current or former spouse/partner had ever (or during the last 12 months) forced them to have sex.

The independent variables that we examined in this paper were informed by extant literature and based on their unadjusted correlation with the dependent variables in our preliminary analyses (Table not included). The variables include the following:

i. Education: We distinguished between respondents who had post-primary education and those who had primary education or lower. We hypothesize a negative relationship between post-primary education and experience of IPV;

ii. Current employment status: We compared those who were currently working with those who were not. We hypothesize a negative relationship between being employed and experience of IPV;

iii. Type of place of residence: We made a distinction between urban residents and rural residents. We hypothesize that urban residence will be associated with reduced odds of IPV;

iv. Current age: This variable is measured in single years. We hypothesize a negative association between age and experience of IPV;

v. Current marital union: This variable classifies respondents into three different groups: those currently married and whose marriage was registered; those currently married but whose marriage was not registered; and those who were not currently married. Our hypothesis is that a registered union will be associated with reduced odds of IPV;

vi. Province of residence: We distinguished between residence in North Kivu and South Kivu. We expect to find differences between the two provinces due to the differences in ethnic composition between them; vii. Index for gender equitable attitudes: Derived from 29 statements that assessed attitudes towards gender equity. The statements were measured on Likert-scale and are available upon request from the author. The Cronbach's alpha for scale reliability for the 29 items was 0.818 . We hypothesize a negative correlation between gender-equitable attitudes and experience of IPV.

viii. Personal alcohol consumption: We distinguished between those who did not drink or had never been drunk and those who had ever been drunk (problematic alcohol consumption). We hypothesize 
that problematic alcohol consumption will be associated with increased odds of IPV;

ix. Recent experience of physical IPV: Defined as described above. We used this variable as a correlate of sexual IPV for men and women. We hypothesized a positive association between the two variables;

x. Recent experience of sexual IPV: Defined as described above. We used this variable as a correlate of physical IPV for men and women. We hypothesized a positive association between the two variables;

xi. Partner's alcohol consumption: We distinguish between those whose husband/partner did not drink or had never been drunk and those whose husband/partner had ever been drunk. This variable was assessed only for women;

xii. Partner's controlling behavior: We assessed this variable only for women. It is based on responses to six questions ask if the woman's partner/husband: (1) is jealous if the woman talks with other men; (2) accuses the woman of infidelity; (3) prevents the woman from visiting friends; (4) limits the woman's contacts with her family; (5) insists on knowing the woman's whereabouts at all times; and (6) does not trust the woman. The six items have a Crombach's alpha score of 0.69 . The median score for partner's controlling behaviors was 2 . In the multivariable analysis, we split this score at the median and compared women with a score of 2 or lower with those with a score of 3 or more. By combining the six items to create the variable, we are assuming that all the controlling behaviors are equally important. We hypothesize a positive association of this variable with IPV;

xiii. Current experience of public humiliation by husband/sex partner: This variable was measured through a question that asked women if their husband/partner said or did something to them to humiliate them in front of others. We distinguished between those whose husband partner publicly humiliated them in the last 12 months and those whose husband/partner did not. This variable was assessed only for women and used only in predicting sexual and physical forms of IPV. We hypothesize a positive association with sexual and physical IPV.

\subsection{Analysis}

The analyses performed were two-fold. First, we assessed the prevalence of the two forms of intimate partner violence for men and women, separately. Subsequently, we used logistic regression to identify the factors associated with recent experience of the forms of IPV. We performed separate analyses for men and women.

\section{Results}

\subsection{Characteristics of the Respondents}

Table 1 presents selected characteristics of sexually experienced men and women. The data indicate that there are significant differences between men and women. Specifically, men were more likely than women to have post-primary education, be currently employed and to report problematic use of alcohol. In addition, men were, on average, older than women and less likely to report that their marriage was not registered. The score for gender-equitable attitudes was significantly higher among men compared to women. The data further show that almost a third of the women had a husband or partner with problematic use of alcohol. In addition, more than one fifth of the women had experienced public humiliation (an act of emotional IPV) from their spouse or partner while more than four-fifths had a husband with controlling behaviors.

Table 1. Percent distribution (or mean) of selected socio-demographic, attitudinal, relational and behavioral variables, DRC, 2012

\begin{tabular}{|c|c|c|c|}
\hline $\begin{array}{c}\text { Socio-demographic and Other } \\
\text { Characteristics }\end{array}$ & Men & Women & $\begin{array}{c}\mathrm{p} \\
\text { value }^{1}\end{array}$ \\
\hline $\begin{array}{l}\text { Level of education (\%) } \\
\text { Primary of lower (RC) } \\
\text { Post-primary }\end{array}$ & $\begin{array}{l}28.9 \\
71.1\end{array}$ & $\begin{array}{l}55.4 \\
44.6\end{array}$ & 0.000 \\
\hline $\begin{array}{c}\text { Current employment status (\%) } \\
\text { Not working (RC) } \\
\text { Working }\end{array}$ & $\begin{array}{l}35.1 \\
64.9\end{array}$ & $\begin{array}{l}47.7 \\
52.3\end{array}$ & 0.000 \\
\hline $\begin{array}{c}\text { Type of place of residence }(\%) \\
\text { Rural/semi-urban (RC) } \\
\text { Urban }\end{array}$ & $\begin{array}{l}51.3 \\
48.7\end{array}$ & $\begin{array}{l}51.9 \\
48.1\end{array}$ & 0.794 \\
\hline Mean age in years (sd) & $\begin{array}{c}34.6 \\
(13.2)\end{array}$ & $\begin{array}{c}31.8 \\
(11.4)\end{array}$ & 0.000 \\
\hline $\begin{array}{c}\text { Marital status (\%) } \\
\text { Married, union registered (RC) } \\
\text { Married, union not registered } \\
\text { Not currently married } \\
\end{array}$ & $\begin{array}{l}31.9 \\
34.8 \\
33.3 \\
\end{array}$ & $\begin{array}{l}26.3 \\
44.2 \\
29.5 \\
\end{array}$ & 0.000 \\
\hline $\begin{array}{c}\text { Province }(\%) \\
\text { Sud Kivu }(\mathrm{RC}) \\
\text { Nord Kivu }\end{array}$ & $\begin{array}{l}51.3 \\
48.7\end{array}$ & $\begin{array}{l}51.5 \\
48.5\end{array}$ & 0.924 \\
\hline $\begin{array}{c}\text { Mean score for gender-equitable } \\
\text { attitudes (sd) (range: } 0-28)\end{array}$ & $\begin{array}{l}15.9 \\
(4.8)\end{array}$ & $14.7(4.9)$ & 0.000 \\
\hline $\begin{array}{l}\text { Personal alcohol consumption }(\%) \\
\text { Does not drink/never drunk }(\mathrm{RC}) \\
\text { Sometimes or often drunk }\end{array}$ & $\begin{array}{l}70.0 \\
30.0\end{array}$ & $\begin{array}{l}81.7 \\
18.3\end{array}$ & 0.000 \\
\hline $\begin{array}{c}\text { Partner drinking habits }(\%) \\
\text { Does not drink/never drunk }(\mathrm{RC}) \\
\text { Sometimes or often drunk }\end{array}$ & --- & $\begin{array}{l}70.1 \\
29.9\end{array}$ & --- \\
\hline $\begin{array}{c}\text { Recently experienced public } \\
\text { humiliation }(\%)\end{array}$ & --- & 21.5 & --- \\
\hline $\begin{array}{l}\text { Experienced any controlling } \\
\text { behavior from partner }(\%)\end{array}$ & --- & 85.8 & \\
\hline Number of Respondents & 889 & 1057 & --- \\
\hline
\end{tabular}

${ }^{1}$ For the difference between men and women

\subsection{Prevalence of IPV}

Lifetime prevalence of IPV: Table 2 shows the percent of men and women who had ever experienced physical or sexual forms of IPV. The data showed that the two forms of 
IPV were common among men and women in the study provinces. More than one quarter of men and two in five women had reportedly ever experienced physical aggression from their intimate partner while 15.7 percent of men and about one quarter of women reported ever experiencing sexual IPV. The two forms of IPV were strongly correlated, such that those who experienced one form of IPV were very likely to have experienced the other form. Among women, 63.6 percent of those who reported ever experiencing sexual IPV also reported the physical form. Similarly, among men, about half $(49.6 \%)$ of those that reported sexual IPV also reported physical IPV. The correlation coefficient (CC) between the two forms of IPV was $0.216(p<.0001)$ for men and $0.285(\mathrm{p}<.0001)$ for women.

Table 2. Percent $(95 \% \mathrm{CI})$ reporting lifetime experience of physical and sexual forms of IPV, sexually experienced respondents, by sex

\begin{tabular}{|c|c|c|c|}
\hline Form of IPV & $\begin{array}{c}\text { Men } \\
(\mathrm{n}=889)\end{array}$ & $\begin{array}{c}\text { Women } \\
(\mathrm{n}=1057)\end{array}$ & $\begin{array}{c}\text { Both Sexes } \\
(\mathrm{n}=1946)\end{array}$ \\
\hline Physical IPV *** & $\begin{array}{c}27.2 \\
(24.2,30.1)\end{array}$ & $\begin{array}{l}40.0 \\
(37.0, \\
42.9)\end{array}$ & $\begin{array}{c}34.2 \\
(32.1,36.3)\end{array}$ \\
\hline Sexual IPV $* * *$ & $\begin{array}{c}15.7 \\
(13.3,18.1)\end{array}$ & $\begin{array}{l}25.1 \\
(22.4, \\
27.7)\end{array}$ & $\begin{array}{c}20.8 \\
(19.0,22.6)\end{array}$ \\
\hline $\begin{array}{c}\text { physical or sexual } \\
\text { IPV }^{* * *}\end{array}$ & $\begin{array}{c}34.1 \\
(30.9,37.2)\end{array}$ & $\begin{array}{c}47.3 \\
(44.3, \\
50.3) \\
\end{array}$ & $\begin{array}{c}41.2 \\
(39.1,43.4)\end{array}$ \\
\hline
\end{tabular}

Notes: Significance of differences between the sexes: $* * * \mathrm{p}<.001$

Recent experience of IPV: Recent experience with IPV (that is, within the last 12 months), was relatively high confirming that IPV continues to be a problem in the study population (see Table 3). Almost one in five women had recently experienced physical IPV while a similar proportion had recently experienced forced sex from an intimate partner. Overall, women were reportedly more likely than men to have recently experienced physical or sexual IPV, although the problem was also noticeable among men.

Table 3. Percent $(95 \% \mathrm{CI})$ that experience forms of IPV during the last 12 months, sexually experienced respondents, by sex

\begin{tabular}{|cccc|}
\hline & \multicolumn{3}{c|}{ Percent Reporting } \\
\cline { 2 - 4 } Form of IPV & $\begin{array}{c}\text { Men } \\
(\mathrm{n}=889)\end{array}$ & $\begin{array}{c}\text { Women } \\
(\mathrm{n}=1057)\end{array}$ & $\begin{array}{c}\text { Both } \\
\text { Sexes } \\
(\mathrm{n}=1946)\end{array}$ \\
\hline Physical IPV *** & 13.7 & 19.3 & 16.7 \\
& $(11.4$, & $(16.9$, & $(15.1$, \\
Sexual IPV *** & $16.0)$ & $21.7)$ & $18.4)$ \\
\hline & 11.7 & 18.8 & 15.6 \\
& $(9.6,13.8)$ & $(16.4$, & $(13.9$, \\
& 21.2 & $17.2)$ \\
\hline
\end{tabular}

Notes: Significance of differences between the sexes: ${ }^{* * *} \mathrm{p}<.001$

\subsection{Correlates of IPV}

We performed logistic regression to assess the correlates of recent IPV experience for men and women (Table 4). For both sexes we examined the predictive power of education, employment status, urban residence, age, marital status, province of residence, gender-equitable attitudes, and personal alcohol consumption. In addition, for women, we explored the role of partner drinking habits, partner controlling behaviors, and recent experience of being publicly humiliated by partner; these variables were not assessed for men. Moreover, in order to acknowledge the co-occurrence of both forms of IPV, we included physical violence in the models estimating sexual violence, and vice versa. The results showed that the factors associated with recent experience of IPV differ for men and women. For each sex, the correlates also differ depending on the type of IPV considered.

Table 4. Results (odds ratio) of logistic regression of recent experience of various forms of IPV on selected characteristics, DRC 2012

\begin{tabular}{|c|c|c|c|c|}
\hline \multirow{2}{*}{ Correlates } & \multicolumn{2}{|c|}{ Men } & \multicolumn{2}{|c|}{ Women } \\
\hline & Physical & Sexual & Physical & Sexual \\
\hline $\begin{array}{c}\text { Education } \\
\text { Primary of lower (RC) } \\
\text { Post-primary }\end{array}$ & $\begin{array}{c}1.00 \\
0.62 *\end{array}$ & $\begin{array}{l}1.00 \\
1.37\end{array}$ & $\begin{array}{c}1.00 \\
0.59 *\end{array}$ & $\begin{array}{l}1.00 \\
0.82\end{array}$ \\
\hline $\begin{array}{c}\text { Current employment } \\
\text { Status } \\
\text { Not working }(\mathrm{RC}) \\
\text { Working }\end{array}$ & $\begin{array}{l}1.00 \\
0.60^{*}\end{array}$ & $\begin{array}{l}1.00 \\
0.90\end{array}$ & $\begin{array}{l}1.00 \\
0.88\end{array}$ & $\begin{array}{l}1.00 \\
0.81\end{array}$ \\
\hline $\begin{array}{c}\text { Type of place of } \\
\text { residence } \\
\text { Rural/semi-urban (RC) } \\
\text { Urban } \\
\end{array}$ & $\begin{array}{l}1.00 \\
1.28\end{array}$ & $\begin{array}{l}1.00 \\
1.02\end{array}$ & $\begin{array}{l}1.00 \\
1.52 \%\end{array}$ & $\begin{array}{l}1.00 \\
1.16\end{array}$ \\
\hline Age in years & $0.98 \ddagger$ & 0.98 & $0.97 * *$ & 0.99 \\
\hline $\begin{array}{l}\text { Current Marital Status } \\
\text { Married, union } \\
\text { registered (RC) } \\
\text { Married, union not } \\
\text { registered } \\
\text { Not currently married } \\
\end{array}$ & $\begin{array}{l}1.00 \\
0.98 \\
0.73\end{array}$ & $\begin{array}{l}1.00 \\
1.09 \\
0.78\end{array}$ & $\begin{array}{l}1.00 \\
0.97 \\
0.92\end{array}$ & $\begin{array}{l}1.00 \\
1.03 \\
0.62 \ddagger\end{array}$ \\
\hline $\begin{array}{c}\text { Province } \\
\text { South Kivu (RC) } \\
\text { North Kivu }\end{array}$ & $\begin{array}{l}1.00 \\
1.43 \ddagger\end{array}$ & $\begin{array}{c}1.00 \\
0.54 * *\end{array}$ & $\begin{array}{l}1.00 \\
1.39 \\
\end{array}$ & $\begin{array}{c}1.00 \\
0.62 * *\end{array}$ \\
\hline $\begin{array}{c}\text { Score for } \\
\text { gender-equitable } \\
\text { attitudes }\end{array}$ & 0.96 & $\begin{array}{l}0.88^{* *} \\
*\end{array}$ & $0.95^{*}$ & 0.99 \\
\hline $\begin{array}{c}\text { Personal alcohol } \\
\text { consumption } \\
\text { Does not drink/never } \\
\text { drunk (RC) } \\
\text { Sometimes or often } \\
\text { drunk } \\
\end{array}$ & $\begin{array}{l}1.00 \\
1.13\end{array}$ & $\begin{array}{l}1.00 \\
1.88^{* *}\end{array}$ & $\begin{array}{l}1.00 \\
0.76\end{array}$ & $\begin{array}{l}1.00 \\
1.14\end{array}$ \\
\hline $\begin{array}{l}\text { Recently experienced } \\
\text { physical IPV }\end{array}$ & --- & $\begin{array}{c}5.55^{* *} \\
*\end{array}$ & --- & $\begin{array}{c}2.92 * * \\
*\end{array}$ \\
\hline $\begin{array}{c}\text { Recently experienced } \\
\text { sexual IPV }\end{array}$ & $5.53 * * *$ & --- & $2.91 * * *$ & --- \\
\hline $\begin{array}{l}\text { Partner drinking habits } \\
\text { Does not drink/never } \\
\text { drunk (RC) } \\
\text { Sometimes or often } \\
\text { drunk } \\
\end{array}$ & --- & --- & $\begin{array}{r}1.00 \\
1.76^{* *}\end{array}$ & $\begin{array}{c}1.00 \\
1.80 * *\end{array}$ \\
\hline $\begin{array}{c}\text { Partner's controlling } \\
\text { score } \\
0-2(\mathrm{RC}) \\
3-5 \\
\end{array}$ & --- & --- & $\begin{array}{c}1.00 \\
1.56^{*}\end{array}$ & $\begin{array}{c}1.00 \\
1.60 * \\
\end{array}$ \\
\hline $\begin{array}{l}\text { Recent experience of } \\
\text { public humiliation }\end{array}$ & --- & --- & $4.90 * * *$ & 0.92 \\
\hline $\begin{array}{l}\text { Explained variance } \\
\left(\text { Pseudo- } \mathrm{R}^{2}\right)\end{array}$ & $10.3 \%$ & $15.1 \%$ & $18.5 \%$ & $8.9 \%$ \\
\hline
\end{tabular}

Notes: $(\mathrm{RC})=$ reference category; $* * * \mathrm{p}<.001 ; * * \mathrm{p}<.01 ; * \mathrm{p}<.05 ;+\mathrm{p}<01$ 
Men:

Recent physical IPV in men was a function of employment status, education, and recent experience of sexual form of IPV. Specifically, men who had post-primary education or who were currently employed were significantly less likely to report recent experience of physical IPV compared to their lowly educated or non-working peers. The association between recent physical IPV and recent sexual IPV was positive such that reporting a recent experience of sexual IPV increases the odds of physical IPV more than five-fold. Age and residing in North Kivu were only marginally significant correlates of physical IPV for men. Concerning recent experience of sexual IPV, the significant correlates were personal alcohol consumption, residence in North Kivu, gender-equitable attitudes, and recent experience of physical IPV. Specifically, this form of IPV was higher among men who had the habit of getting drunk and significantly less common in North Kivu compared to South Kivu. Furthermore, sexual IPV was negatively correlated with gender-equitable attitudes and positively associated with recent experience of physical IPV.

Women:

The variables significantly associated with recent experience of physical IPV for women included education, age, partner's drinking habits, partner's controlling behavior, recent experience of sexual IPV, and recent experience of public humiliation from an intimate partner. The data showed a strong negative association between age and current experience of physical IPV such that one year increase in age is associated with a 3 percent reduction in the odds of experiencing this type of IPV. The odds of experiencing physical IPV are 41 percent lower among women with post-primary education compared to their peers with primary or a lower level of education. Recent experience of public humiliation from an intimate partner increases the odds of reporting physical IPV almost five-fold. Similarly, recent experience of sexual IPV increases the odds of reporting physical IPV almost three-fold. A unit increase in the score for gender-equitable score was associated with a 5 percent decrease in the odds of experiencing physical IPV. In addition, having a controlling husband/partner increases the odds of experiencing physical IPV about 56 percent. Finally, women whose partners had the habit of getting drunk were 76 percent more likely to report experiencing physical IPV compared to their peers whose partners did not have this habit. As for sexual IPV, significant correlates for women are residence in North Kivu, recent experience of physical IPV, partner's controlling behaviors, and partner drinking habits. Substantively, having a partner with a tendency to get drunk increases the odds of recent experience of sexual IPV almost two-fold while residing in North Kivu decreases the odds by 38 percent. The relationship between sexual IPV and partner's controlling behaviors is positive such that having a partner with a high level of controlling behaviors is associated with a 60 percent increase in the odds of experiencing sexual IPV.

\section{Discussion}

This manuscript used data from a large-scale survey to assess the prevalence and correlates of physical and sexual IPV among men and women in two provinces in eastern DRC. The findings are consistent with those of previous studies from developed and developing countries, and show that IPV is a very common problem in DRC. $[6,9,10]$ Our data however reveal a higher prevalence of IPV for men and women than what some studies in African countries had found. For example, we found that 40.0 percent of women had ever experienced physical IPV compared to 29.3 percent that Gass and his colleagues[6] found in their South Africa study. In their ten-country study, Hindin, Kishor and Ansara[48] found that 20 percent of women in Malawi, 28 percent in Zimbabwe and 29 percent in Rwanda had ever experienced physical IPV. However, other studies have found prevalence of physical IPV comparable to, or even higher than what we found in this study (e.g., Hindin, Kishor \& Ansara[48] for Kenya and Zambia; Garcia-Moreno et al[9] for Tanzania and Ethiopia). Consistent with previous studies, our study found that women were more likely than men to be victims of physical or sexual forms of IPV. [5,6,7,8,42] Our study also revealed that the various forms of IPV co-occur in many men and women. This finding echoes results of previous studies. $[17,48,49]$

Consistent with what Gass and his colleagues [6] found in their South Africa study, our study revealed commonalities but also differences in the factors associated with recent experience of IPV for men and women. For example, age was not a very strong predictor of recent experience of physical violence for men whereas this variable was highly significant for women. In contrast, employment status was a significant correlate for men but not for women. Post-primary education and recent experience of sexual violence were significant correlates for men and women. For women, the other significant correlates of physical IPV were recent experience of partner-inflicted public humiliation, partner's controlling behaviors, and partner's problematic use of alcohol.

The absence of a strong association between age and experience of IPV for men was consistent with what Breiding and colleagues[5] found in their US sample and O'Leary and colleagues[42] found in Ukraine but conflicts with the finding of Gass and colleagues[6] found in South Africa. The finding of a significant association between education and experience of physical violence for men is consistent with what most studies have found.[5,6,42] Similarly, the significant negative relationship between education and experience of IPV for women is as expected and consistent with findings from other studies.[6,37] The finding that husband/partner's problematic use of alcohol is a strong predictor of physical IPV is consistent with 
previous studies.[8,39,42,50,51].

The factors associated with experience of sexual violence are mostly different for men and women and generally different from those associated with the experience of physical IPV. For both men and women, residence in North Kivu was associated with reduced odds of experience of sexual violence. As expected, gender-equitable attitudes were associated with reduced odds of experience of sexual violence for men but this variable was not significant for women. Similarly, personal problematic use of alcohol significantly increases the odds of experiencing sexual IPV for men but not for women. The strong relationship between partner problematic use of alcohol and experience of sexual IPV makes intuitive sense and is consistent with findings from other studies.[52-55]

Gender-equitable attitudes were significantly associated with sexual IPV for men but physical IPV for women. It is interesting that manifesting gender equitable attitudes is protective for men against sexual IPV. While the reason for this finding is not entirely clear, examining the situation from both feminist theoretical and symbolic interactionism perspectives offers a plausible explanation. It is indeed reasonable to argue that people with gender-equitable attitudes would be more respectful and considerate of their partners and thereby less likely to resort to, or attract, violence in cases of marital conflict.

This study has some limitations that warrant mention. First, the fact that the data are cross-sectional, collected at one point in time precludes any attempt to infer causality. The relationships documented are mere associations although the strength of some of these associations indicates that the findings should be taken seriously when designing programs to address IPV in DRC. Second, the data were based on self-reported experiences and could have been affected by memory lapse, social desirability and other biases. By focusing on recent experience to identify correlates of IPV, we can reasonably assume that the problem of memory lapse is minimized. Third, although our study showed that the various forms of IPV co-occur in the same individuals, the data did not allow us to demonstrate whether one form of IPV leads to another or if there are some underlying factors that foster perpetration or victimization of these forms of IPV. Future studies should use longitudinal data to examine the nature of the relationship among the various forms of IPV. Fourth, due to data limitations, our study did not explore the prevalence of emotional IPV and partner controlling behavior for men. This is another issue that could be a worthwhile area of focus for future research. Fifth, the data do not allow us to ascertain if the acts of IPV reported were perpetrated by a current or former spouse/partner. Some of the correlates have to do with the behaviors of a spouse/partner who may or may not have been the same whose violent acts were reported. This possible discrepancy between the perpetrator and the current partner may have introduced some bias into the estimated models. Finally, our measure of physical IPV covers various violent actions of varying degree of severity.
Indeed, it is reasonable to assume that the correlates of life-threatening acts of physical violence are different from those associated with acts of physical violence that are potentially non-life-threatening.

\section{Conclusion}

Intimate partner violence is a common problem among men and women in Eastern DRC and efforts to address the problem are urgently needed. There are clear relationships between the various forms of IPV, indicating the need for a comprehensive approach. Programs that focus on increasing audience understanding about the various forms of IPV, improving partner communication, reducing alcohol abuse, changing negative gender norms, and that specifically target female youth and women with low education should be part of a comprehensive approach to prevent IPV.

\section{Acknowledgements}

The authors acknowledge the participation of the respondents who took the time to participate in the survey and provide the information analyzed in this manuscript. We also appreciate the contribution of Neetu John and Rose Zulliger (Bloomberg School of Public Health, Johns Hopkins University); Alessia Radice, Cynthia Scarlett, Tony Samamba, Jessica Ramsel and James Campbell (International Medical Corps) for their contribution to the design and implementation of the original research that produced the data analyzed in this manuscript. The research reported in this manuscript has been funded in full with the generous support of the International Medical Corps, through the cooperative agreement AID-6Z3-A-I0-00013-00 from the United States Agency for International Development. The views and opinions expressed herein are those of the authors and shall not, in any way whatsoever, be construed to reflect the views or opinions of International Medical Corps, the United States Agency for International Development, or any of International Medical Corps's other donors.

\section{REFERENCES}

[1] M. Nanivazo. Sexual violence in the Democratic Republic of the Congo. United Nations University human Rights, 2012. Online Available from: http://unu.edu/publications/articles/s exual-violence-in-the-democratic-republic-of-the-congo.html

[2] W. Wakabi. Sexual Violence Increasing in the Democratic Republic of Congo. The Lancet, Vol. 371, No. 9606, 15-16, 2008.

[3] K. Johnson, J. Scott, B. Rughita, M. Kisielewski, J. Asher, R. Ong, L. Lawry. Association of sexual violence and human rights violations with physical and mental health in locations 
of the Eastern Democratic Republic of the Congo, Journal of the American Medical Association, Vol. 304, No. 5, 553-562, 2010

[4] S.Bartels, J. Scott, J. Leaning, J. Kelly, D. Mukwege, N. Joyce, M. Vanrooyen. Sexual violence trends between 2004 and 2008 in South Kivu, Democratic Republic of Congo, Prehospital and Disaster Medicine, Vol. 26, No. 6, 408-13, 2012

[5] M. J. Breiding, M. C. Black, G. W. Ryan. Prevalence and risk factors of intimate partner violence in eighteen U.S. states/territories, 2005, American Journal of Preventive Medicine, Vol. 34, No. 2, 112-118, 2008

[6] J. D. Gass, D. J. Stein, D. R. Williams, S. Seedat. Gender Differences in risk for intimate partner violence among South African adults, Journal of Interpersonal Violence, Vol. 26, No. 14, 2764-2789, 2011

[7] H. Khalifeh, J. Hargreaves, L. M. Howard, I. Birdthistle. Intimate partner violence and socioeconomic deprivation in England: Findings from a national cross-sectional survey, American Journal of Public Health, Vol. 103, No. 3, $462-472,2013$

[8] P. Tjaden, N. Thoennes. Full report of the prevalence, incidence, and consequences of violence against women: Findings from the National Violence Against Women Survey, US Department of Justice, Office of Justice Programs, National Institute of Justice, Washington, DC, 2000

[9] C. Garcia-Moreno, H. Jansen, M. Ellsberg, L. Heise, C. H. Watts, on behalf of the WHO Multi-country Study on Women's Health and Domestic Violence against Women Study Team. Prevalence of intimate partner violence: Findings from the WHO multi-country study on women's health and domestic violence, The Lancet, Vol. 368, No. 9543, 1260-1269, 2006.

[10] F. Hassan, L. S. Sadowski, S. I. Bangdiwala, B. Vizcarra, L. Ramiro, C. S. De Paula, I. A. S. Bordin, M. K. Mitra. Physical intimate partner violence in Chile, Egypt, India and the Philippines, Injury Control and Safety Promotion, Vol. 11, No. 2, 111-116, 2004.

[11] J. C. Campbell. Health consequences of intimate partner violence, The Lancet, Vol. 359, No. 9314, 1331-36, 2002.

[12] L. Heise, C. Garcia Moreno. Violence by intimate partners, In: Krug EG et al., eds. World report on violence and health. World Health Organization, Geneva, 87-122, 2002.

[13] H. Jackson, E. Philp, R. L. Nuttall, L. Diller. Traumatic brain injury: A hidden consequence for battered women, Professional Psychology: Research and Practice, Vol. 33, No. 1, 39-45, 2002.

[14] I. Ruiz-Pérez, J. Plazaola-Castaño, M. del Río-Lozano. Physical health consequences of intimate partner violence in Spanish women, European Journal of Public Health, Vol. 17, No. 5, 437-443, 2007. doi: 10.1093/eurpub/ck1280

[15] M. Ellsberg, H. Jansen, L. Heise, C. H. Watts, C. Garcia-Moreno, on behalf of the WHO Multi-country Study on Women's Health and Domestic Violence against Women Study Team. Intimate partner violence and women's physical and mental health in the WHO multi-country study on women's health and domestic violence: an observational study, The Lancet, Vol. 371, No. 9619, 1165-1172, 2008
[16] A. L. Coker, P. H. Smith, M. K. Fadden. Intimate partner violence and disabilities among women attending family practice clinics, Journal of Women's Health, Vol. 14, No. 9, 829-838, 2005.

[17] A. L. Coker, P. H. Smith, L. Bethea, M. R. King, R. E. McKeown. Physical health consequences of physical and psychological intimate partner violence, Archives of Family Medicine, Vol. 9, No. 5, 451-457, 2000

[18] K. Kendall-Tackett, R. Marshall, K. Ness. Chronic pain syndromes and violence against women, Women and Therapy, Vol. 26, No. 1/2, 45-56, 2003.

[19] M. A. Dutton, B. L. Green, S. I. Kaltman, D. M. Roesch, T. A. Zeffiro, E. D. Krause. Intimate partner violence, PTSD, and adverse health outcomes, Journal of Interpersonal Violence, Vol. 21, No. 7, 955-968, 2006.

[20] J. M. Golding. Intimate partner violence as a risk factor for mental disorders: A meta-analysis, Journal of Family Violence, Vol. 14, No. 2, 99-132, 1999.

[21] B. Vizcarra, F. Hassan, W. M. Hunter, S. R. Muñoz, L. Ramiro, and C. S. De Paula. Partner violence as a risk factor for mental health among women from communities in the Philippines, Egypt, Chile, and India, Injury Control and Safety Promotion, Vol. 11, No. 2, 125-129, 2004.

[22] N. N. Sarkar. The impact of intimate partner violence on women's reproductive health and pregnancy outcome, Journal of Obstetrics and Gynaecology, Vol. 28, No. 3, 266-271, 2008.

[23] E. Valladares, M. Ellsberg, R. Pena, U. Hogberg, L. A, Persson. Physical partner abuse during pregnancy: A risk factor for low birth weight in Nicaragua, Obstetrics and Gynecology, Vol. 100, No. 4, 700-705, 2002.

[24] C. J. Campbell, L. A. Lewandowski. Mental and physical health effects of intimate partner violence and physical health effects of intimate partner violence in women and children, Psychiatric Clinics of North America, Vol. 20, No. 2, 353-374, 1997.

[25] L. K. Ackerson, S. V. Subramanian. Intimate partner violence and death among infants and children in India, Pediatrics, Vol. 124, No. 5, e878-e889, 2009. doi:10.1542/peds.2009-0524

[26] M. M. Moretti, I. Obsuth, C. L. Odgers, P. Reebye. Exposure to maternal vs. paternal partner violence, PTSD, and aggression in adolescent girls and boys, Aggressive Behavior, Vol. 32, No. 4, 385-395, 2006.

[27] L. A. McCloskey, C. Williams, U. Larsen. Gender inequality and intimate partner violence among women in Moshi, Tanzania, International Family Planning Perspectives, Vol. 31, No. 3, 124-130, 2005.

[28] C. Peek-Asa, L. Maxwell, A. Stromquist, P. Whitten, M. A. Limbos, J. Merchant. Does parental physical violence reduce children's standardized test score performance? Annals of Epidemiology, Vol. 17, No. 11, 847-853, 2007.

[29] S. L. Wood, M. S. Sommers. Consequences of intimate partner violence on child witnesses: A systematic review of the literature, Journal of Child and Adolescent Psychiatric Nursing, Vol. 24, No. 4, 223-236, 2011. doi: 10.1111/j.1744-6171.2011.00302.x

[30] R. Jewkes. Intimate partner violence: causes and prevention, 
The Lancet, Vol. 359, No. 9315, 1423-1429, 2002

[31] L. Jeyaseelan, L. S. Sadowski, S. Kumar, F. Hassan, L. Ramiro, B. Vizcarra. World studies of abuse in the family environment-risk factors for physical intimate partner violence, Injury Control and Safety Promotion, Vol. 11, No. 2, 117-124, 2004.

[32] S. M. Stith, K. H. Rosen, K. A. Middleton, A. L. Busch, K. Lundeberg, R. P. Carlton. The intergenerational transmission of spouse abuse: A metaanalysis, Journal of Marriage and Family, Vol. 62, No. 3, 640-654, 2000.

[33] N. Abrahams, R. Jewkes. Effects of South African men's having witnessed abuse of their mothers during childhood on their levels of violence in adulthood, American Journal of Public Health, Vol. 95, No. 10, 1811-1816, 2005.

[34] D. Gil-Gonzalez, C. Vives-Cases, M. T. Ruiz, M. Carrasco-Portino, C.AlvarezDardet. Childhood experiences of violence in perpetrators as a risk factor of intimate partner violence: A systematic review, Journal of Public Health, Vol. 30, No. 1, 14-22, 2007.

[35] J. Gupta, J. G. Silverman, D. Hemenway, D. Acevedo-Garcia, D. J. Stein, D. R. Williams. Physical violence among intimate partners and related exposures to violence among South African men, Canadian Medical Association Journal, Vol. 179, No. 6, 535-541, 2008.

[36] F. Naeem, M. Irfan, Q. A. Zaidi, D. Kingdon, M. Ayub. Angry wives, abusive husbands: Relationship between domestic violence and psychosocial variables, Women's Health Issues, Vol. 18, No. 6, 453-462, 2008. http://dx.doi.org/10.1016/j.whi.2008.08.002.

[37] S. R. Kimuna, Y. K. Djamba. Gender based violence: Correlates of physical and sexual wife abuse in Kenya, Journal of Family Violence, Vol. 23, No. 5, 333-342, 2008. doi 10.1007/s10896-008-9156-9

[38] WHO/LSHTM. Preventing intimate partner and sexual violence against women: taking action and generating evidence, World Health Organization/ London School of Hygiene and Tropical Medicine, Geneva/London, 2010.

[39] N. Abrahams, R. Jewkes, R. Laubscher, M. Hoffman. Intimate partner violence: Prevalence and risk factors for men in Cape Town, South Africa, Violence and Victims, Vol. 21, No. 2, 247-264, 2006.

[40] K. L. Chan. Sexual violence against women and children in Chinese societies, Trauma, Violence and Abuse, Vol. 10, No. $1,69-85,2009$.

[41] R. Jewkes, J., Levin, L. Penn-Kekana. Risk factors for domestic violence: Findings from a South African cross-sectional study, Social Science and Medicine, Vol. 55, No. 9, 1603-1617, 2002.

[42] K. D. O'Leary, N. Tintle, E. J. Bromet, S. F. Gluzman. Descriptive epidemiology of intimate partner aggression in Ukraine, Social Psychiatry and Psychiatric Epidemiology, Vol. 43, No. 8, 619-626, 2008.

[43] S. L. Miller, M. L. Meloy. Women's use of force: Voices of women arrested for domestic violence, Violence Against Women, Vol. 12, No. 1, 89-115. 2006. doi:10.1177/1077801205277356

[44] S. C. Swan, D. L. Snow. The development of a theory of women's use of violence in intimate relationships, Violence Against women, Vol. 12, No. 11, 1026-1045, 2006. doi: $10.1177 / 1077801206293330$

[45] S. C. Swan, D. L. Snow. Behavioral and psychological differences among abused women who use violence in intimate relationships, Violence Against Women, Vol. 9, No. 1, 75-109, 2003.

[46] M. S. Harned. Abused women or abused men? An examination of the context and outcomes of dating violence, Violence and Victims, Vol. 16, No. 3, 269-85, 2001.

[47] M. A. Straus. Measuring intrafamily conflict and violence: The conflict tactics (CT) scales, Journal of Marriage and the Family, Vol. 41, No. 1, 75-88, 1979

[48] .M. J. Hindin, S. Kishor, D. L. Ansara. Intimate partner violence among couples in 10 DHS Countries: Predictors and health outcomes, DHS Analytical Studies No. 18, Macro International Inc, Calverton, Maryland, USA, 2008.

[49] D. Meekers, S. C. Pallin, P. Hutchinson. Prevalence and correlates of physical, psychological, and sexual intimate partner violence in Bolivia, Global Public Health: An International Journal for Research, Policy and Practice, Vol. 8, No. 5, 588-606, 2013. doi:10.1080/17441692.2013.776093

[50] R. Caetano, J. Schafer, C. B. Cunradi. Alcohol-related intimate partner violence among white, black, and Hispanic couples in the United States, Alcohol Research and Health, Vol. 25, No. 1, 58-65, 2001.

[51] M. P. Thompson, J. B. Kingree. The roles of victim and perpetrator alcohol use in intimate partner violence outcomes, Journal of Interpersonal Violence, Vol. 21, No. 2, 163-77, 2006.

[52] H. M. Foran, K. D. O'Leary. Alcohol and intimate partner violence: A meta-analytic review, Clinical Psychology Review, Vol. 28, No. 7, 1222-1234, 2008.

[53] T. Abramsky, C. H. Watts, C. Garcia-Moreno, K. Devries, L. Kiss, M. Ellsberg, H. A. F. M. Jansen, L. Heis. What factors are associated with recent intimate partner violence? Findings from the WHO multi-country study on women's health and domestic violence, BMC Public Health, Vol. 11, No. 1, 109, 2011. doi:10.1186/1471-2458-11-109

[54] D. F. Flake, R. Forste. Fighting families: Family characteristics associated with domestic violence in five Latin American countries, Journal of Family Violence, Vol. 21, No. 1, 19-29, 2006. doi:10.1007/s10896-005-9002-2

[55] L. Coker, P. H. Smith, R. E. McKeown, M. J. King. Frequency and correlates of intimate partner violence by type: physical, sexual, and psychological battering, American Journal of Public Health, Vol. 90, No. 4, 553-559, 2000 . 